\title{
Synthesis of MIL-100(Fe) at Low Temperature and Atmospheric Pressure
}

\author{
Jing Shi, Shengtao Hei, Huanhuan Liu, Yanghe Fu, Fumin Zhang, \\ Yijun Zhong, and Weidong Zhu
}

Key Laboratory of the Ministry of Education for Advanced Catalysis Materials, Institute of Physical Chemistry, Zhejiang Normal University, 321004 Jinhua, China

Correspondence should be addressed to Fumin Zhang; fumin.zhang@gmail.com

Received 10 May 2013; Revised 7 September 2013; Accepted 16 September 2013

Academic Editor: Giuseppe Gattuso

Copyright ( 2013 Jing Shi et al. This is an open access article distributed under the Creative Commons Attribution License, which permits unrestricted use, distribution, and reproduction in any medium, provided the original work is properly cited.

\begin{abstract}
MIL-100(Fe), a mesoporous metal-organic framework (MOF), has a large BET specific surface area and pore volume with the presence of a significant amount of accessible Lewis acid metal sites upon dehydration. The structural characteristics of MIL-100(Fe) make it a good candidate for potential applications in gas storage, separation, and heterogeneous catalysis. Mainly, this MOF is obtained by the hydrothermal synthesis in a Teflon-lined autoclave at high temperature $\left(>150^{\circ} \mathrm{C}\right)$ under static conditions. However, this method has several disadvantages such as high temperature, high (autogenous) pressure, long time, and comparable low MOF yield. Therefore, development of a facile method for synthesis of MIL-100(Fe) is vitally important for fundamental understanding and practical application. Herein, MIL- $100(\mathrm{Fe})$ is synthesized by a facile low-temperature $\left(<100^{\circ} \mathrm{C}\right)$ synthesis route at atmospheric pressure by reaction of metallic iron and trimesic acid in water. Due to our synthesis is conducted with agitation, higher MOF yield (>90\%) still could be achieved, suggesting that this simple and energy saving method has the potential to be used practically.
\end{abstract}

\section{Introduction}

Metal-organic frameworks (MOFs) are porous crystalline hybrid organic-inorganic solids constructed by metal ions coordinated to multidentate organic ligands leading to threedimensional extended networks having channels and cavities [1-3]. Due to their outstanding properties such as permanent porosity, high surface area, and pore volume, the use of MOFs in various applications, for example, gas storage, separation, and catalysis is being explored [4-6]. Among the tens of thousands of known MOFs, there are several transition-metal MOFs that have shown highly hydrothermal and chemical stability. These include mesoporous iron(III) carboxylate (MIL-100(Fe)), which has a rigid zeotype crystal structure, consisting of 2.5 and $2.9 \mathrm{~nm}$ mesoporous cages accessible through window sizes of ca. 0.55 and $0.86 \mathrm{~nm}$, respectively [7]. Notably, MIL-100(Fe) exhibits a high thermal stability $\left(>270^{\circ} \mathrm{C}\right)$ and a remarkable chemical resistance (organic solvents or water under reflux). In addition, the presence of accessible coordinatively unsaturated metal sites allows the coordination of different species, making it an interesting candidate for many potential applications [8-13].
MIL-100(Fe) is mainly obtained by a hydrothermal synthesis in a Teflon-lined autoclave at high temperature $\left(>150^{\circ} \mathrm{C}\right)$ under static conditions [7-11]. However, this method has several disadvantages, such as high temperature, high (autogeneous) pressure, long time, and comparable low MOF yield. In order to shorten synthesis time, García Márquez and coworkers applied a microwave-assisted solvothermal route to obtain MIL-100(Fe) due to the fact that microwave irradiation can cause molecular-level heating, which leads to homogeneous and quick thermal reactions [14]. But the crystallinity of the obtained MOF is comparably low, and this method also faces the difficulty in large scale production from an application's point of view. In addition, Ahmed and coworkers developed a dry gel conversion method for the preparation of MIL-100(Fe) by reaction of metallic iron and trimesic acid in the presence of steam in a Teflon-lined autoclave [15]; however, high temperature $\left(160^{\circ} \mathrm{C}\right)$ and long time $(4 \mathrm{~d})$ still presist in their method. Nevertheless, the obtained MIL-100(Fe) showed a comparable low BET specific surface area. Thus, from fundamental understanding and viable application's points of 
view, development of a facile method for MOFs synthesis is very important. To the best of our knowledge, there has been no report on the synthesis of MIL-100(Fe) carried out at low temperature $\left(<100^{\circ} \mathrm{C}\right)$ and atmospheric pressure with short time (less than $1 \mathrm{~d}$ ) up to now.

In the current work, we develop a method for synthesis of MIL-100(Fe) at low temperature $\left(<100^{\circ} \mathrm{C}\right)$ and atmospheric pressure by reaction of metallic iron and trimesic acid under reflux. Due to the fact that our synthesis is conducted with agitation, the obtained MIL-100(Fe) has merits like high yield and large BET specific surface area, accompanied with low synthesis temperature and short synthesis time, suggesting that this simple unappreciated method could be applied to MOFs syntheses in large scale.

\section{Experimental Section}

MIL-100(Fe) is synthesized by a facile low-temperature $\left(<100^{\circ} \mathrm{C}\right)$ synthesis route with agitation at atmospheric pressure under reflux by reaction of trimesic acid with metallic iron in the presence of $\mathrm{HF}, \mathrm{HNO}_{3}$, and $\mathrm{H}_{2} \mathrm{O}$. Typically, the reactant mixture with the composition of $1.0 \mathrm{Fe}: 1.0$ trimesic acid : $2.0 \mathrm{HF}: 0.5 \mathrm{HNO}_{3}: 100 \mathrm{H}_{2} \mathrm{O}$ was charged into a PTFE flask with agitation and kept at $95^{\circ} \mathrm{C}$ for $12 \mathrm{~h}$ under reflux. After the crystallization, the obtained product was sufficiently purified by hot deionized water followed by drying. The chemical formula of the prepared MIL-100(Fe) was found to be $\left[\mathrm{Fe}_{3} \mathrm{O}\left(\mathrm{H}_{2} \mathrm{O}\right)_{2} \mathrm{~F}_{0.8}(\mathrm{OH})_{0.2}\right)\left\{\mathrm{C}_{6} \mathrm{H}_{3}\left(\mathrm{CO}_{2}\right)_{3}\right\}_{2} \cdot n \mathrm{H}_{2} \mathrm{O}(n \approx$ 14.8)], based on the elemental analysis.

The powdered X-ray diffraction (XRD) patterns were performed on a Philips PW3040/60 diffractometer using $\mathrm{CuK \alpha}$ radiation $(\lambda=0.1541 \mathrm{~nm})$ in a scanning range of $1.5 \sim 3^{\circ}$. Nitrogen adsorption at $-196^{\circ} \mathrm{C}$ in a Micromeritics ASAP 2020 instrument was used to determine the textural properties as BET surface area between 0.05 and 0.20 relative pressure and pore volume at 0.95 relative pressure. The pore size distribution curves were determined from the adsorption isotherms by the Density Functional Theory (DFT) method. Scanning Electron Microscopy (SEM) was measured in a JEOL $2100 \mathrm{~F}$ setup for morphology analysis. The infrared (IR) spectra were collected on a Nicolet NEXUS670 Fourier transform infrared spectrophotometer in $\mathrm{KBr}$ disks at room temperature.

\section{Results and Discussion}

The XRD pattern of the prepared MIL-100(Fe) is illustrated in Figure 1. The pattern of the obtained MIL-100(Fe) is very similar to the simulated result reported in the literature [7], confirming the formation of the metal-organic framework. The SEM images of the synthesized MIL-100(Fe) are shown in Figure 2. As one can see, the synthesized MIL-100(Fe) is mainly octahedral in shape, although the particles are not uniform in size.

The textural properties of the synthesized MIL-100(Fe) assessed from $\mathrm{N}_{2}$ adsorption isotherm are presented in Figure 3(a). The synthesized MIL-100(Fe) reveals an adsorption isotherm characteristic of microporous solid. The corresponding BET surface area and pore volume for the

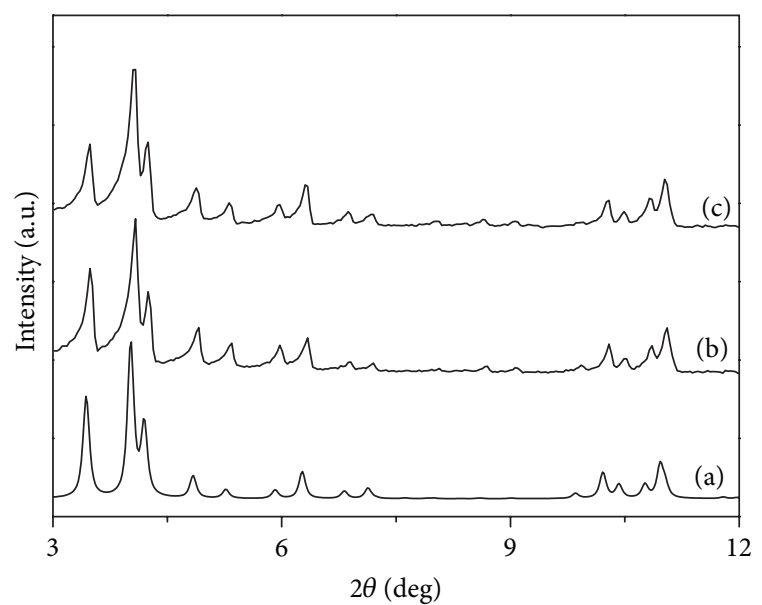

FIGURE 1: XRD patterns of the simulated MIL-100(Fe) (a), the fresh MIL-100(Fe) (b), and the one after one month (c).

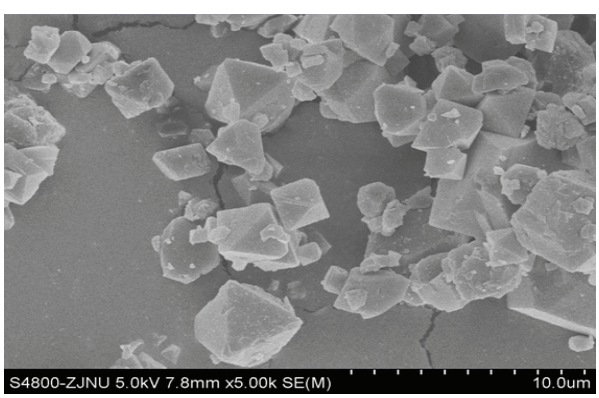

(a)

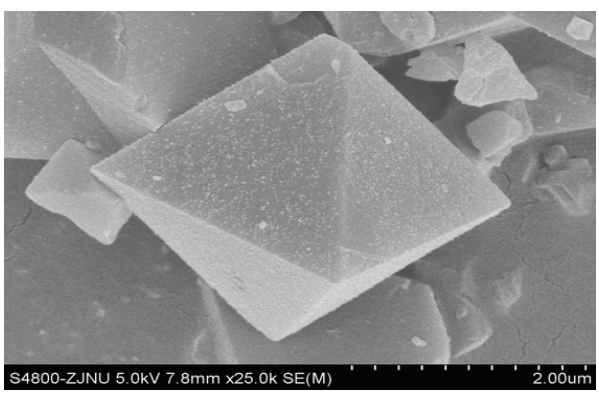

(b)

Figure 2: SEM images with different scale bars.

developed MIL-100(Fe) are $1754 \mathrm{~m}^{2} \mathrm{~g}^{-1}$ and $0.80 \mathrm{~cm}^{3} \mathrm{~g}^{-1}$, respectively. The DFT pore size distribution curve of MIL$100(\mathrm{Fe})$ (Figure 3(b)) displays two different pore sizes centered at about 1.9 and $2.4 \mathrm{~nm}$, respectively, confirming the presence of the two types of mesoporous cages in MIL$100(\mathrm{Fe})$. However, these values are underestimated by the DFT method in comparison with van der Waals diameters calculated from the crystalline structure $(2.5 \mathrm{~nm}$ and $2.9 \mathrm{~nm}$, resp.) [7]. This trend was also reported by Canioni and coworkers in the literature [16].

It has been clarified that BET specific surface areas and pore volumes of MOFs synthesized by different methods depend on the degree of their purification as well as their 


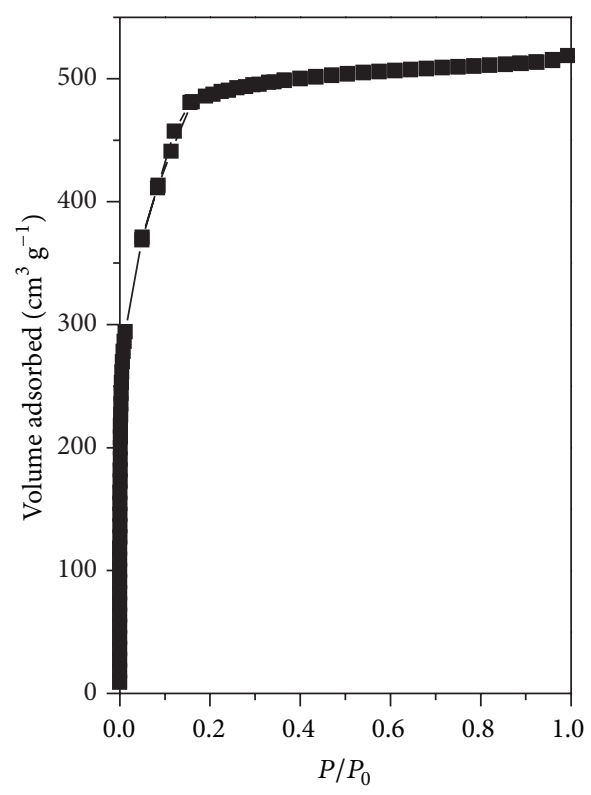

(a)

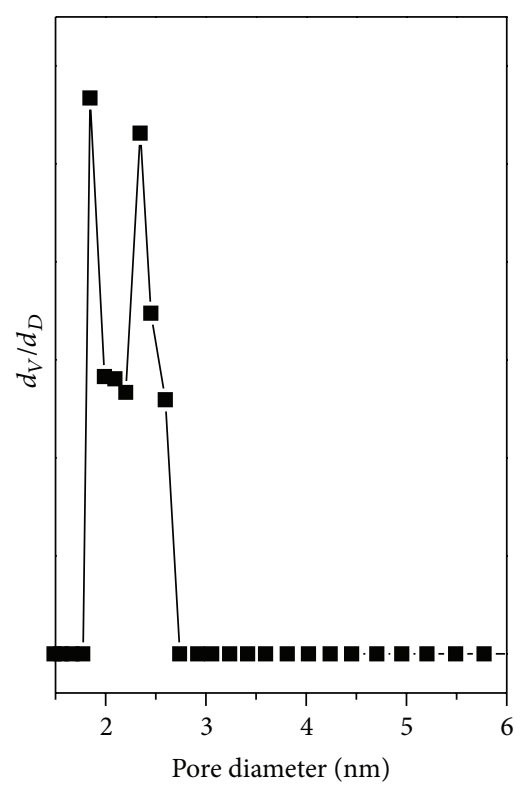

(b)

FIGURE 3: $\mathrm{N}_{2}$ adsorption isotherm at $-196^{\circ} \mathrm{C}$ (a) and DFT pore size distribution of MIL-100(Fe) (b).

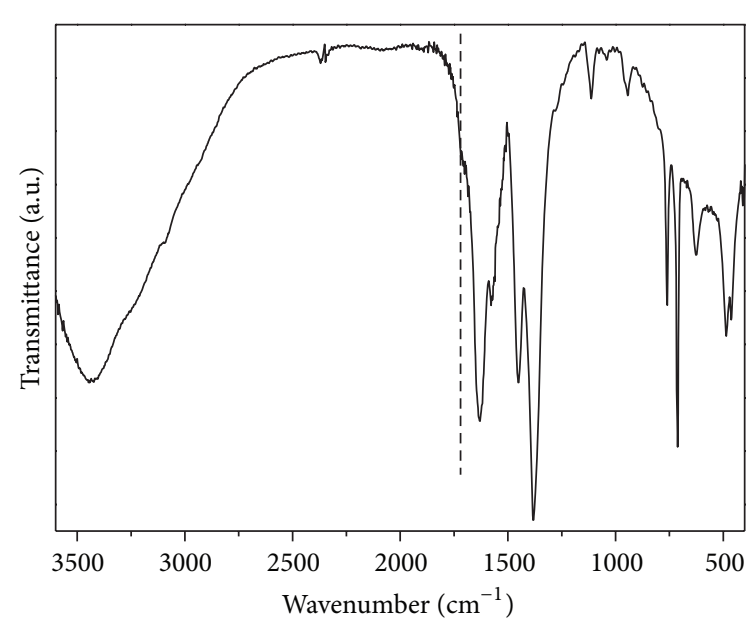

Figure 4: FT-IR spectrum of the synthesized MIL-100(Fe).

crystallinity $[8,17]$. This is often due to the presence of residual impurities such as nonreacted carboxylic acids in the pores and interparticle grains, coordinated carboxylates, and/or inorganic cations or anions from starting metal salts, besides the content of amorphous phases or other crystalline impurities. Therefore, this often leads to the discrepancy of textural properties of samples even if from the same batch of synthesis. FT-IR spectrum of the synthesized MIL-100(Fe) is shown in Figure 4, from which one could observe that the peak ascribed to $\mathrm{C}=\mathrm{O}$ stretching vibration at $1710-1720 \mathrm{~cm}^{-1}$ in the sample, assigned to residual trimesic acid [8], is not apparent, suggesting that the purification procedure applied here is very effective in removing residual trimesic acid.

On the basis of the XRD, SEM, FT-IR, and $\mathrm{N}_{2}$ adsorption results, it may be concluded that MIL-100(Fe) could be successfully prepared by the method developed in this context. The synthesis conditions and textural properties of MIL-100(Fe) reported in the literature were further compared in Table 1. It should be noted that our synthesis is carried out under a dynamic condition in which mass transfer could be significantly intensified; therefore, the synthesis temperature is much lower than that under static conditions applied in the literature. In addition, high (autogeneous) pressure is required in the literature for the conventional hydrothermal synthesis $[7-9,11]$, while in the current case the synthesis was carried out at atmospheric pressure. Therefore, it is another benefit when safety operation is taken into consideration. Furthermore, a high MOF yield (>90\%) could be achieved for the MIL-100(Fe) synthesized in the current case, probably because of the lower water fraction in the synthesis recipe (see Section 2) than that needed in the literature [7-9, 11], besides being assisted by stirring during the synthesis. Additionally, the developed MIL-100(Fe) is highly stable in air for more than one month, and no change in XRD pattern was found for the sample during this period (see Figure 1(c)). The high stability is one of the most important features for practical application. On the other hand, the BET specific surface area and pore volume for the current case are moderate compared to the results reported in the literature, probably due to the different purification and crystallinity $[8,17]$, as well as the different $p / p_{0}$ range for BET area calculation. Moreover, it should be admitted that it is difficult to handle HF due to its harmful nature, although it plays an important role in the synthesis of MIL-100(Fe). Thus, the use of HF hinders mass production of MOFs. Therefore, more work is still needed in order to successfully synthesize MOFs under HF-free conditions. Luckily, Seo and coworkers also synthesized MOF-100(Fe) in HF-free conditions [11], with the BET specific surface area and pore volume larger than those 
TABLE 1: Synthesis conditions and textural properties of MIL$100(\mathrm{Fe})$ measured by $\mathrm{N}_{2}$ adsorption at $-196^{\circ} \mathrm{C}$ in comparison with other references.

\begin{tabular}{lccccc}
\hline Synthesis method & $\begin{array}{c}\text { Temperature } \\
{ }^{\circ} \mathrm{C}\end{array}$ & $\begin{array}{c}\text { Time } \\
\mathrm{h}\end{array}$ & $\begin{array}{c}S_{\mathrm{BET}} \\
\mathrm{m}^{2} / \mathrm{g}\end{array}$ & $\begin{array}{c}V_{\text {total }} \\
\mathrm{cm}^{3} / \mathrm{g}\end{array}$ & Reference \\
\hline $\mathrm{HT}^{\mathrm{a}}$ & 165 & 240 & 1190 & 0.56 & {$[15]$} \\
$\mathrm{DGG}^{\mathrm{b}}$ & 165 & 96 & 1340 & 0.63 & {$[15]$} \\
$\mathrm{HT}^{\mathrm{a}}$ & 150 & 144 & $2800^{\mathrm{c}}$ & - & {$[7]$} \\
$\mathrm{HT}^{\mathrm{a}}$ & 160 & 12 & 1800 & 1.15 & {$[11]$} \\
$\mathrm{HT}^{\mathrm{a}}$ & 160 & 8 & 2320 & 1.2 & {$[18]$} \\
$\begin{array}{l}\text { Low-temperature } \\
\text { synthesis }\end{array}$ & 95 & 12 & 1754 & 0.80 & $\begin{array}{c}\text { Current } \\
\text { work }\end{array}$ \\
\hline
\end{tabular}

${ }^{a}$ Conventional hydrothermal method; ${ }^{\text {b }}$ dry gel conversion method.

${ }^{\mathrm{c}}$ Langmuir surface area.

obtained in the current case, suggesting that commercial MIL-100(Fe) in large scale is expected in the near future.

\section{Conclusions}

A facile method for the synthesis of MIL-100(Fe) at low temperature and atmospheric pressure has been developed by reaction of trimesic acid with metallic iron in the presence of $\mathrm{HF}, \mathrm{HNO}_{3}$, and $\mathrm{H}_{2} \mathrm{O}$ under reflux. This simple synthesis method will pay a new and facile way for the synthesis of MOFs for practical applications.

\section{Acknowledgments}

The financial supports by the National Natural Science Foundation of China (20806075), the Program for Changjiang Scholars and Innovative Research Team in Chinese Universities (IRT0980), and the Zhejiang Provincial Natural Science Foundation of China (LY13B030002) are gratefully acknowledged.

\section{References}

[1] O. M. Yaghi, M. O’Keeffe, N. W. Ockwig, H. K. Chae, M. Eddaoudi, and J. Kim, "Reticular synthesis and the design of new materials," Nature, vol. 423, no. 6941, pp. 705-714, 2003.

[2] S. Kitagawa, R. Kitaura, and S.-I. Noro, "Functional porous coordination polymers," Angewandte Chemie, vol. 43, no. 18, pp. 2334-2375, 2004.

[3] G. Férey, "Hybrid porous solids: past, present, future," Chemical Society Reviews, vol. 37, pp. 191-214, 2008.

[4] M. P. Suh, H. J. Park, T. K. Prasad, and D.-W. Lim, "Hydrogen storage in metal-organic frameworks," Chemical Reviews, vol. 112, no. 2, pp. 782-835, 2012.

[5] J.-R. Li, J. Sculley, and H.-C. Zhou, "Metal-organic frameworks for separations," Chemical Reviews, vol. 112, no. 2, pp. 869-932, 2012.

[6] A. Corma, H. García, and F. X. Llabrés I Xamena, "Engineering metal organic frameworks for heterogeneous catalysis," Chemical Reviews, vol. 110, no. 8, pp. 4606-4655, 2010.
[7] P. Horcajada, S. Surblé, C. Serre et al., "Synthesis and catalytic properties of MIL-100(Fe), an iron(III) carboxylate with large pores," Chemical Communications, no. 27, pp. 2820-2822, 2007.

[8] M. G. Plaza, A. M. Ribeiro, A. Ferreira et al., "Separation of $\mathrm{C}_{3} / \mathrm{C}_{4}$ hydrocarbon mixtures by adsorption using a mesoporous iron MOF: MIL-100(Fe)," Microporous and Mesoporous Materials, vol. 153, pp. 178-190, 2012.

[9] A. Dhakshinamoorthy, M. Alvaro, H. Chevreau et al., "Iron(III) metal-organic frameworks as solid Lewis acids for the isomerization of $\alpha$-pinene oxide," Catalysis Science and Technology, vol. 2, no. 2, pp. 324-330, 2012.

[10] L. Kurfiřtová, Y.-K. Seo, Y. K. Hwang, J.-S. Chang, and J. Čejka, "High activity of iron containing metal-organic-framework in acylation of p-xylene with benzoyl chloride," Catalysis Today, vol. 179, no. 1, pp. 85-90, 2012.

[11] Y.-K. Seo, J. W. Yoon, J. S. Lee et al., "Large scale fluorinefree synthesis of hierarchically porous iron(III) trimesate MIL$100(\mathrm{Fe})$ with a zeolite MTN topology," Microporous and Mesoporous Materials, vol. 157, pp. 137-145, 2012.

[12] M. Opanasenko, M. Shamzhy, and J. Čejka, "Solid acid catalysts for Coumarin synthesis by the Pechmann reaction: MOFs versus zeolites," Chem CatChem, vol. 5, pp. 1024-1031, 2013.

[13] M. Opanasenko, A. Dhakshinamoorthy, J. Čejka, and H. Garcia, "Deactivation pathways of the catalytic activity of MetalOrganic Frameworks in condensation reactions," ChemCatChem, vol. 5, pp. 1553-1561, 2013.

[14] A. García Márquez, A. Demessence, A. E. Platero-Prats et al., "Green microwave synthesis of MIL-100(Al, Cr, Fe) nanoparticles for thin-film elaboration," European Journal of Inorganic Chemistry, vol. 2012, no. 32, pp. 5165-5174, 2012.

[15] I. Ahmed, J. Jeon, N. A. Khan, and S. H. Jhung, "Synthesis of a metal-organic framework, iron-benezenetricarboxylate, from dry gels in the absence of acid and salt," Crystal Growth \& Design, vol. 12, pp. 5878-5881, 2012.

[16] R. Canioni, C. Roch-Marchal, F. Sécheresse et al., "Stable polyoxometalate insertion within the mesoporous metal organic framework MIL-100(Fe)," Journal of Materials Chemistry, vol. 21, no. 4, pp. 1226-1233, 2011.

[17] M. Faustini, J. Kim, G. Y. Jeong et al., "Microfluidic approach toward continuous and ultra-fast synthesis of metal-organic framework crystals and hetero-structures in confined microdroplets," Journal of the American Chemical Society, 2013.

[18] J. W. Yoon, Y.-K. Seo, Y. K. Hwang et al., "Controlled reducibility of a metal-organic framework with coordinatively unsaturated sites for preferential gas sorption," Angewandte Chemie, vol. 49, no. 34 , pp. 5949-5952, 2010. 

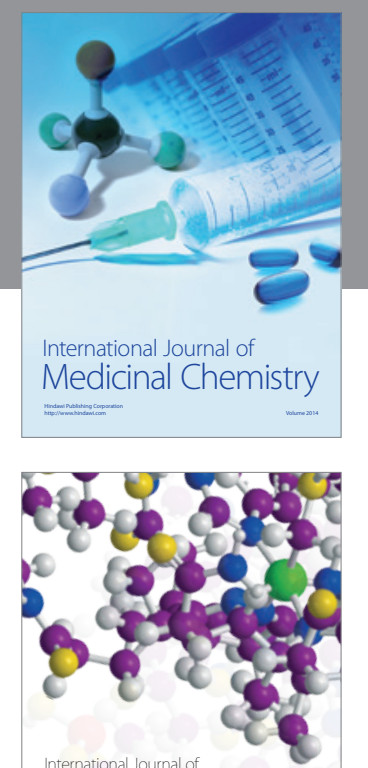

\section{Carbohydrate} Chemistry

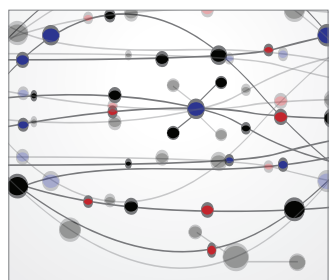

The Scientific World Journal
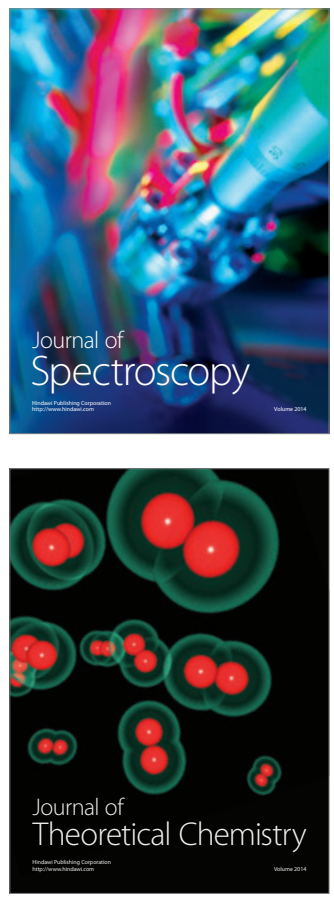
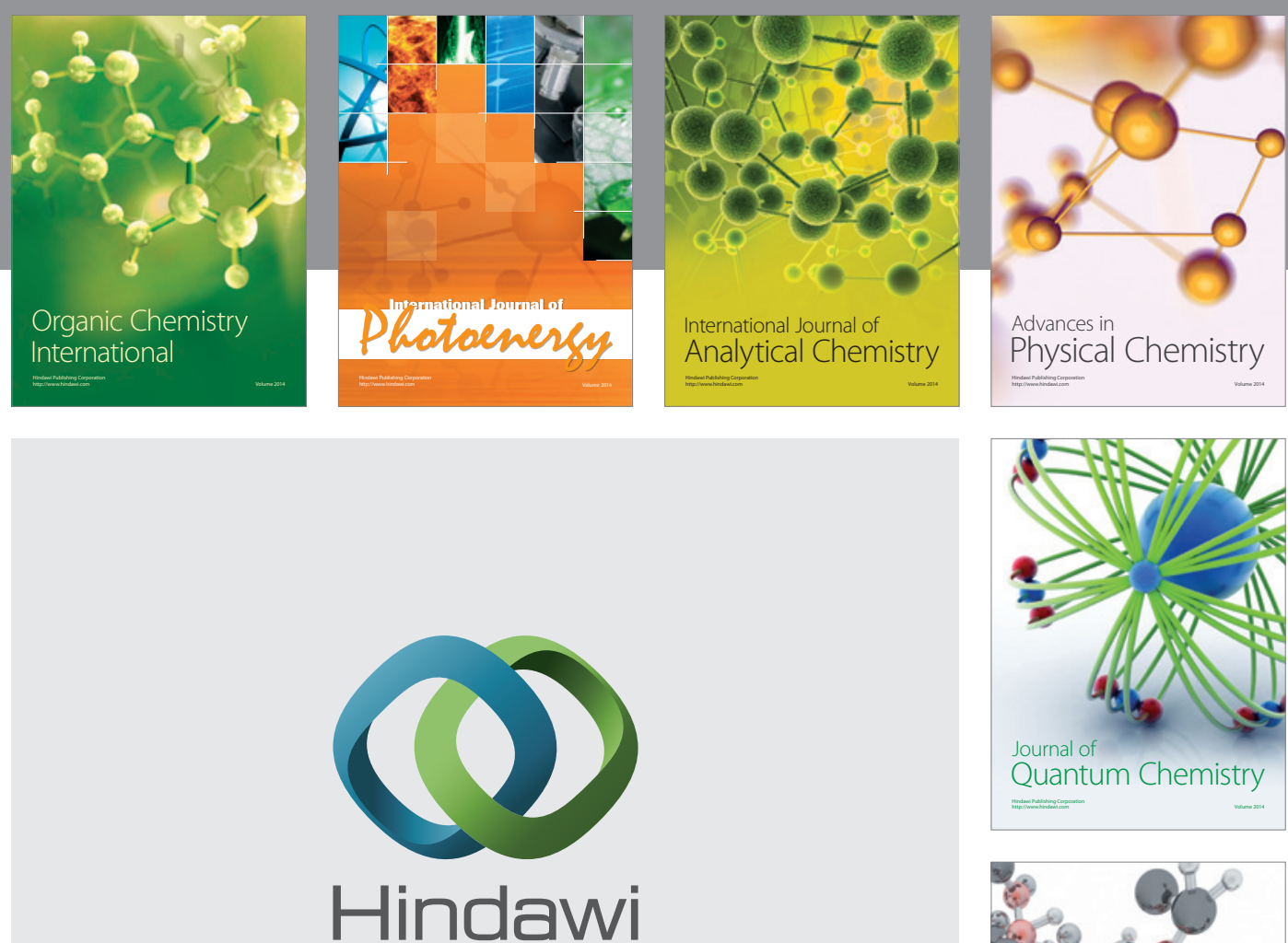

Submit your manuscripts at

http://www.hindawi.com

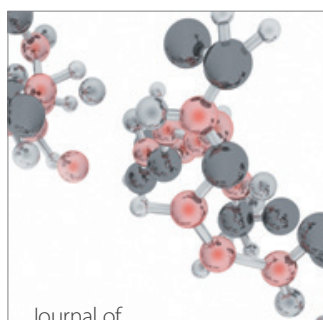

Analytical Methods

in Chemistry

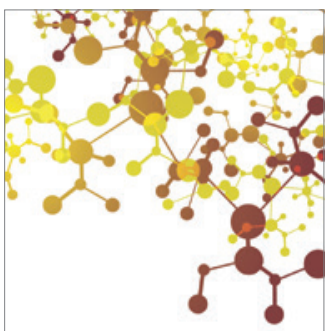

Journal of

Applied Chemistry

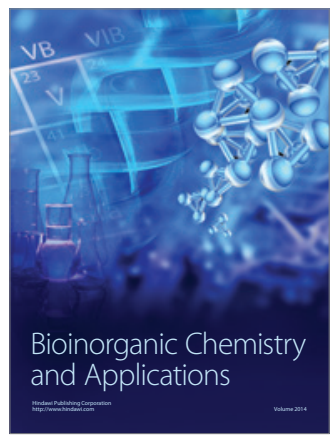

Inorganic Chemistry
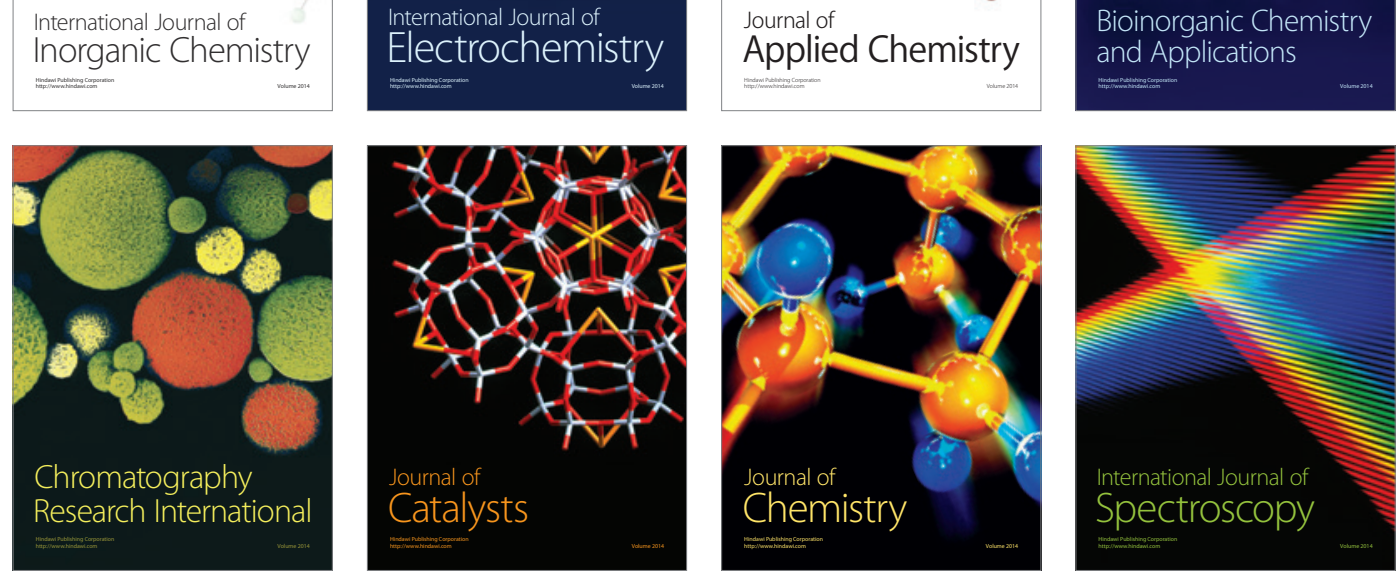